\title{
Charge-coupled device imaging of rapid calcium transients in cultured arterial smooth muscle cells
}

\author{
J. J. LINDERMAN ${ }^{1,2}$, L. J. HARRIS ${ }^{2,}$, , L.L. SLAKEY ${ }^{2}$ and D. J. GROSS ${ }^{2}$ \\ ${ }^{1}$ Department of Chemical Engineering, University of Michigan Ann Arbor, Michigan, USA \\ 2 Department of Biochemistry and Program in Molecular and Cellular Biology, University of \\ Massachusetts, Amherst, Massachusetts, USA
}

Abstract - Transient changes in the concentration of intracellular free calcium are associated with the transduction of primary signals and the subsequent employment of $\mathrm{Ca}^{2+}$ as a second messenger in a multitude of cell types. These transients, typically monitored with the calcium-sensitive fluorescent dye Fura-2, are known to occur with a time course in the order of seconds. In order to accurately monitor such rapid changes in intracellular free calcium concentration in both single cells and simultaneously in several cells in a single fleld, we have developed a digital fluorescence imaging system based on a charge-coupled device (CCD) camera. We report here on the detailed kinetics of calcium increases in cultured arterial swine smooth muscle cells in response to the agonist ATP.

A variety of studies has implicated the calcium ion as a second messenger in the transduction of a variety of primary signals. The treatment of both transformed and untransformed cells with agonists such as nucleotides, hormones, growth factors, and neurotransmitters has been shown to result in a stimulated increase in the concentration of cytosolic free calcium. Several studies have shown that the source of this calcium may be the extracellular medium, suggesting the opening of plasma membrane calcium channels as a part of the response to agonist [1-3], and/or the release of intracellular stores of calcium, a response which occurs in the absence of extracellular calcium [2-6]. In smooth muscle cells, the intracellular stores of calcium are located in the sarcoplasmic reticulum (SR), and some agonists can stimulate the release of

\footnotetext{
"Present address: Radiology Department, University of Massachusetts Medical Center, 55 Lake Avenue N, Worcester, MA 01605, USA
}

calcium from these stores [7-9].

A variety of techniques has been used to measure both steady state and transient cytosolic calcium ion concentrations. Populations of adherent or suspended cells loaded with the fluorescent calcium indicator Fura-2 and examined using a fluorometer showed that the cell population as a whole may respond to agonists with a calcium transient that rises in a few seconds and then falls back to a baseline concentration or to an elevated

The following abbreviations are used: SMC, cultured arterial smooth muscle cell; SR, sarcoplasmic reticulum; CCD, charge-coupled device; DME, Dulbecco's modified Eagles medium; GM1, growth medium one; MEM, minimum essential medium; GM2, growth medium two; DM, defined medium; PDGF, platelet derived growth factor, Fura-2/AM, Fura-2 acetoxymethyl ester; DMSO, dimethylsulfoxide; HEPES, 4-(2-hydroxyethyl)-1-piperazine ethanesulfonic acid; HBS, HEPES-buffered saline; UV, ultraviolet F334, fluorescent intensity at $334 \mathrm{~nm}$; F365, fluorescent intensity at $365 \mathrm{~nm}$; PBS, phosphate-buffered saline; EDTA, ethylenediaminetetra- acetic acid; $\left[\mathrm{Ca}^{2+}\right] \mathrm{i}$, intracellular free $\mathrm{Ca}^{2+}$ concentration. 
concentration over a period of minutes $[1,3]$. The measurement of sub-second kinetics of the calcium response in Fura-2 loaded platelets using stopped-flow fluorometry demonstrated that the population responds to a variety of agonists with a calcium rise in less than one second [5]. Data may also be obtained from single cells using photomultiplier [10] or imaging techniques [11]; stimulated calcium transients in single cells occur rapidly as well $[2,6,12]$. For example, the intracellular calcium concentrations of individual $\mathrm{BC} 3 \mathrm{H}-1$ muscle cells stimulated with phenylephrine were observed to oscillate with a frequency of approximately $2 \mathrm{~min}^{-1}$ [13]. Thus it is evident that transients in the concentration of intracellular free calcium may be rapid, occurring in the order of a few seconds or less.

We have developed a quantitative digital fluorescent imaging system based on a chargecoupled device (CCD) camera that can resolve rapid calcium transients in single cells. Multiple cells within the same field of view can be imaged simultaneously, allowing temporal and spatial measurement of the free calcium concentration within each cell. The use of a CCD as an imag- ing device offers several advantages: linearity, high resolution, photometric accuracy, and geometric stability $[14,15]$. In addition, the user may elect to reduce spatial resolution and/or the size of the area that is imaged to gain imaging speed or to use the CCD as an image storage device, as detailed below.

To accurately determine the intracellular calcium concentration at a point in time using the calcium-sensitive fluorescent indicator Fura-2, a pair of images of the same field must be obtained, each one taken at a different excitation wavelength. Our system is designed to collect these two images with very little time between the two exposures, thereby minimising errors of temporal registration for rapidly changing signals. The time required to collect and store a pair of images increases with image size and exposure time. As detailed later, the minimum time between the two wavelength images is $200 \mathrm{~ms}$.

Using our digital fluorescence imaging system, we have examined the detailed kinetics of transients in intracellular calcium concentration in individual cultured arterial smooth muscle cells (SMC) stimulated with ATP. ATP, which acts as a constrictor in some smooth muscle beds and as a relaxant in others [16], is co-released with several neurotransmitters [17]. It may also be released from stimulated platelets [18]. Slakey [19] estimated that ATP may reach smooth muscle cells and neighbouring endothelial cells at micromolar concentrations. An ATP-induced rise in intracellular free calcium has been observed in populations of suspended rat aortic smooth muscle cells [20] while isolated arterial smooth muscle cells from rabbit ear have been shown to contain an ATP-activated $\mathrm{Ca}^{2+}$-permeable ion channel [21]. In the present study, we have examined the ATP-stimulated transients in intracellular free calcium in individual adherent SMC from pig aorta.

\section{Materials and Methods}

\section{Cell and flow chamber preparation}

Smooth muscle cells from pig aortas were isolated and cultured as described previously [22]. Briefly, medial tissue was minced into $1 \mathrm{~mm}$ pieces and incubated in Dulbecco's modified Eagles medium (DME; Gibco, Grand Island, NY, USA) supplemented with $0.3 \%$ collagenase at $37^{\circ} \mathrm{C}$ for $4 \mathrm{~h}$. The digest was then centrifuged and the pellet resuspended in growth medium one (GM1), consisting of DME, formulation $43-1600$ as supplied by Gibco, and supplemented with $3.5 \mathrm{~g} / \mathrm{l}$ additional glucose ( $4.5 \mathrm{~g} / 1$ total glucose), $4 \mathrm{mM}$ glutamine, non-essential amino acids' solution for MEM as supplied by Gibco, $200 \mathrm{U} / \mathrm{ml}$ penicillin, $0.2 \mathrm{mg} / \mathrm{ml}$ streptomycin, $0.6 \mathrm{mg} / \mathrm{ml}$ tylocine, and $10 \%$ fetal calf senum, and placed in a T-25 flask. Cells attached and grew to confluence within 7 to 10 days. Cells were then subcultured in growth medium two (GM2; identical to GM1 except for the omission of tylocine, non-essential amino acids, and the reduction of the glucose concentration to $1 \mathrm{~g} / \mathrm{l}$ total) for 2 to 3 passages before use. Approximately 2-3 days before an experiment, the cells were returned to GM1.

Coverslips were prepared by placement of a few drops of a dilute fibronectin solution (gift from the laboratory of E. Westhead) on No. 1 glass coverslip surfaces, incubation of the coverslips at $37^{\circ} \mathrm{C}$ and 
$5 \% \mathrm{CO}_{2}$ for at least $30 \mathrm{~min}$, and subsequent removal of the solution from the surface by suction. Adherent cells were removed from confluent flasks by treatment with $0.05 \%$ trypsin/versene solution and were plated at approximately a 1:2.5 dilution onto fibronectin-coated coverslips in GM1. This cell dilution was chosen to ensure subconfluence at the time of imaging, so that individual cells could easily be distinguished. Cells were incubated overnight, and the following day the cells were rinsed and the medium was changed to a serum-free defined medium (DM) containing DME supplemented as described by Libby and O'Brien [23]. Cells were cultured in this serum-free medium for $24 \mathrm{~h}$.

Cells on coverslips were loaded with calcium-sensitive dye by a 30 min incubation at $37^{\circ} \mathrm{C}$ in a $5 \% \mathrm{CO}_{2}$ atmosphere with Fura-2 acetoxymethly ester (Fura-2/AM; Molecular Probes, Eugene, OR, USA). The Fura-2/AM was dissolved in dry dimethylsulfoxide (DMSO) at a stock concentration of $1 \mathrm{mM}$ and mixed with DM to a concentration of $2 \mu \mathrm{M}$ Fura-2/AM and $0.1 \%$ DMSO. Each coverslip contained approximately $10^{5}$ cells; the total volume of DM containing Fura-2/AM that was applied to the coverslip was $1.5 \mathrm{ml}$. Coverslips were then rinsed several times with HEPES-buffered saline (HBS; $20 \mathrm{mM}$ HEPES, $125 \mathrm{mM} \mathrm{NaCl}, 5.4 \mathrm{mM} \mathrm{KCl} .1 .8 \mathrm{mM} \mathrm{CaCl}, 0.8$ $\mathrm{mM} \mathrm{MgSO} 4,5.5 \mathrm{mM}$ D-glucose), mounted in a flow chamber, and viewed immediately. Cells examined for autofluorescence were not incubated with Fura-2/AM but were otherwise prepared in an identical fashion.

The flow chamber (Fig. 1) consisted of a $6 \mathrm{~mm}$ thick stainless steel plate with a vertical hole $13 \mathrm{~mm}$ in diameter through its centre. The coverslip containing the SMC was placed in a shallow slot on the bottom face of the plate and secured using petroleum jelly. A clean coverslip was mounted on the top face of the plate and anchored in place using a molten 1:1:1 mixture of petroleum jelly, lanolin and paraffin, thus forming a cylindrical chamber with a volume of approximately $0.8 \mathrm{ml}$. The flow chamber allows gravity-fed flow in from a $1.5 \mathrm{ml}$ reservoir above and to one side of the chamber, through a $1.5 \mathrm{~mm}$ diameter hole drilled at an angle through the plate and ending just above the coverslip covered with cells, and out through a small channel at the top of the chamber on the side opposite from the inlet. A small tube applied continuous suction to remove any excess fluid. A thin copper plate was placed beneath the flow chamber to help support the coverslip and to aid in heat conduction.

Cells and the surrounding medium in the flow chamber were maintained at $37^{\circ} \mathrm{C}$. A circulating constant temperature water bath pumped water through copper tubing wrapped around the objective lens and through copper tubing soldered to a copper temperature stage. The copper stage was insulated from the microscope stage by Teflon spacers, and the cell-covered coverslip in the flow chamber was placed directly over the objective through an opening in the temperature stage.

\section{Agonist introduction}

Stimulants were introduced into the flow chamber by injection of approximately $2.5 \mathrm{ml}$ of a $37^{\circ} \mathrm{C}$ solution of the agonist in HBS into the flow chamber reservoir. The addition took 2-3 s, and one chamber volume of solution flowed into the chamber within $2 \mathrm{~s}$ of the start of the injection. ATP was obtained from Sigma (St Louis, MO, USA). The non-fluorescent calcium ionophore Br-A23187 was obtained from Molecular Probes.

\section{Instrumentation}

A schematic of the imaging system is shown in Figure 1. The fluorescence epi-illumination system is based on a 75 watt $\mathrm{Hg}$-Xe arc lamp (Hamamatsu Corp., Bridgewater, NJ, USA) and a pair of monchromators (model H2O, Instruments SA Inc., Metuchen, NJ, USA, each equipped with a KM $524.00 .2301200 \mathrm{~g} / \mathrm{mm}$ grating blazed at $330 \mathrm{~nm}$ ), the latter used in place of interference filters to allow convenient tuning of excitation wavelengths [10]. The lamp was chosen for its stability and long life in addition to its high brightness at the $\mathrm{Hg}$ spectral lines of 334 and $365 \mathrm{~nm}$. We chose to employ monochromators rather than interference filters primarily for the ease of tuning that the monochromators provide. Although we commonly use the $\mathrm{Hg}$ spectral lines for fluorescence excitation, 


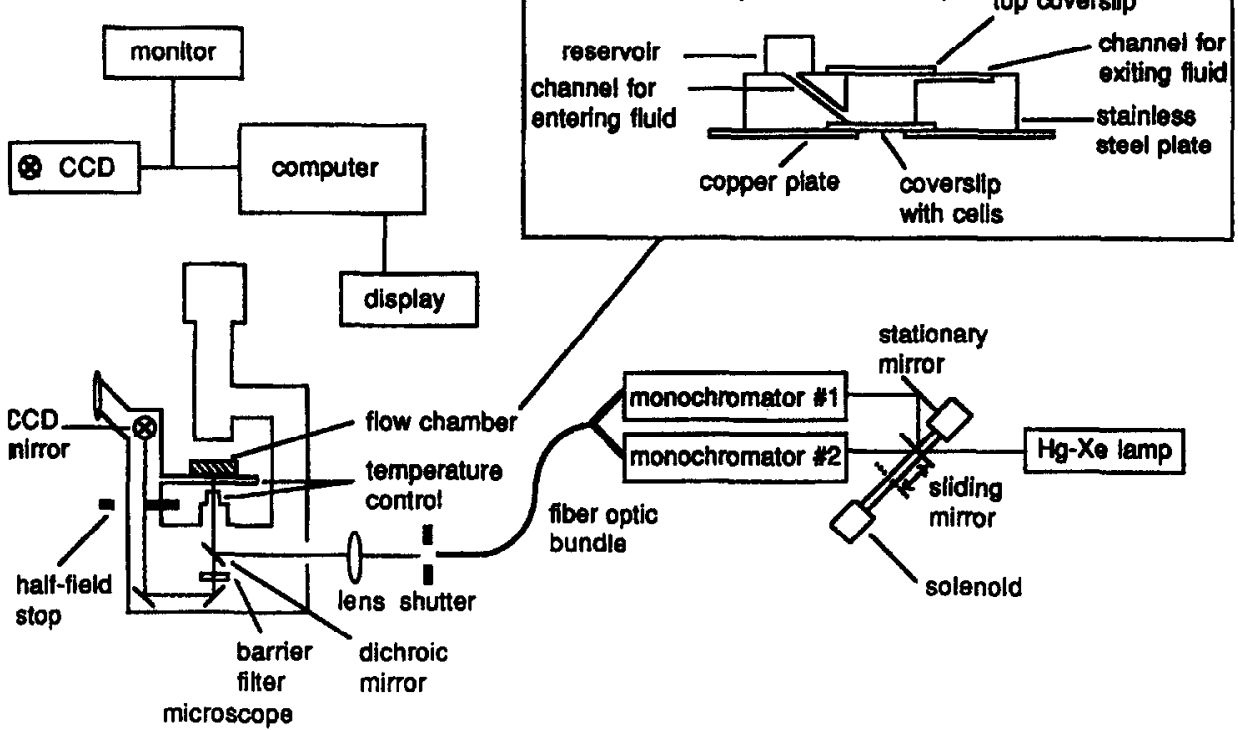

FIg. 1 Schematic diagram of the illumination and detection system. The sliding mirror, shutter, and CCD operation are computer controlled. Inset: Schematic diagram of the flow chamber

all intermediate wavelengths are easily accessible by a simple turn of the monochromator tuning knob. Additionally, the spectral transmission properties of the monochromators are variable by the choice of entrance and exit slits. For Fura-2 imaging the upper monochromator was set to $365 \mathrm{~nm}$ center wavelength with an entrance slit of $2 \mathrm{~mm}$ while the lower monochromator center wavelength was set to $334 \mathrm{~nm}$ with a $4 \mathrm{~mm}$ entrance slit. As the exit port of each monochromator was coupled a rectangular cross section fiber optic bundle of $2 \mathrm{~mm}$ width (see Fig. 1 and below), the upper monochromator had a triangular bandpass profile peaked at $365 \mathrm{~nm}$ of 8 nm width at half maximum transmission with nearly zero transmission below $357 \mathrm{~nm}$ or above $373 \mathrm{~nm}$. The lower monochromator had a trapezoidal bandpass profile centered at $334 \mathrm{~nm}$ of $16 \mathrm{~nm}$ width at half maximum transmission and nearly zero transmission below $320 \mathrm{~nm}$ and above $348 \mathrm{~nm}$. According to the manufacturer's specifications, the relative overlap of the two spectral regions chosen for Fura-2 excitation is $<10^{-5}$. Although we have done no direct comparisons between our monochromators and interference filters, it is possible in theory to obtain more light from a monochromator than from an interference filter. In practice, the size of the diffraction grating and optics associated with the monochromator as well as the wavelength dispersion of the grating determine the transmission efficiency of the monochromator. A straightforward discussion of monochromators can be found in [24]. Fluorescence excitation of the cells therefore occurs at $334 \mathrm{~nm}$ and $365 \mathrm{~nm}$, corresponding to two spectral lines of the $\mathrm{Hg}-\mathrm{Xe}$ arc. When the sliding mirror is moved out of the light path, light is directed into the lower monochromator. A solenoid drive under computer control stably repositions the mirror in under 200 ms.

The exit ports of both monochromators were directly coupled to the two ends $(2 \mathrm{~mm}$ wide by 8 $\mathrm{mm}$ high) of a $51 \mathrm{~cm}$ long bifurcated quartz fiber optic bundle (Volpi Manufacturing USA, Auburn, NY, USA) which terminates in a $6.4 \mathrm{~mm}$ diameter circular cross section randomised bundle directing the light through a computer controlled electronic shutter (A.W. Vincent Associates, Inc., Rochester, NY, USA) with an open/close time of less than 5 ms. According to data from Volpi Manufacturing, the transmissivity of this length of fiber is $60 \%$ from 900 to $450 \mathrm{~nm}$, dropping to $55 \%$ at $300 \mathrm{~nm}$. After passing through a $75 \mathrm{~mm}$ focal length fused silica biconvex lens, the light entered the epi-illumination port of a Zeiss IM-35 inverted microscope (Carl 
Zeiss, Inc., Thomwood, NY, USA) equipped with quartz epi-illumination optics and a Nikon $40 \mathrm{x} / 1.3$ NA CF Fluor UV lens (Nikon Inc. Instrument Division, Garden City, NJ, USA). A Zeiss FT 395 dichroic mirror and a flow fluorescence long-pass barrier filter with $50 \%$ cutoff at $399 \mathrm{~nm}$ (Schott Glass Technologies, Duryea, PA, USA) completed the fluorescence system.

Images were detected by a CCD instrumentation camera (Photometrics, Ltd., Tuscon, AZ, USA) equipped with a $390 \times 584$ pixel Texas Instruments 4849 CCD chip thermoelectrically cooled to approximately $-45^{\circ} \mathrm{C}$ to reduce thermal noise. The chip allows image collection at very high quantum efficiencies (20-60\% at visible wavelengths) with a high degree of linearity and low readout noise (in the order of 15 photoelectron equivalents). The analog image is digitised to 12 bit resolution and was transmitted to the computer via a $500 \mathrm{kHz}$ IEEE-488 interface (National Instruments, Austin, TX, USA).

Computer control of the illumination system (mirror placement, shutter opening and closing) and the CCD camera was accomplished via a Masscomp 5500 computer (Concurrent Computer Corp., Oceanport, NJ, USA). A 14 Mflop Masscomp array processor enhances image computations during and after data collection. A Masscomp GA-1000 graphics subsystem, which included a pair of $1152 \mathrm{x}$ 910 by 12 bit deep image planes and an independent graphics processor, was used for image display. Because 2 of the bit planes were used for overlay graphics, 10 bit planes are available for high resolution image display.

\section{Operation of the $C C D$}

The CCD may be operated in one or more of several specialised modes, as shown in Figure 2 . Straightforward operation allows a full-frame $390 \mathrm{x}$ 584 image to be collected on and read from the CCD chip; the time required to digitise and store the full frame is approximately $1.5 \mathrm{~s}$. Alternatively, data may be read from a portion (or subarray) of the entire field; the readout and storage time is reduced from the time for a full-frame readout and storage approximately in proportion to the size of the subarray chosen. The operation of the $C C D$ in subarray mode thus allows the same lateral resolution as a full-frame image, although over a smaller area of the field.

The CCD is also programmed to bin or combine, the photoelectrons contained in adjacent pixels at the time of readout, prior to digitisation. Binning 2 $x 2$, for example, combines the charge of 2 pixels in the $\mathrm{x}$-direction and 2 pixels in the y-direction to form an array of 'superpixels'. The readout time for a binned image is reduced from the full frame, unbinned image readout time in proportion to the size of the final image - i.e. a $2 \times 2$ binned image takes approximately $1 / 4$ the readout time of a full frame image. Since a major source of image noise is generated during image readout, combining pixel charge before readout produces a superior signal to noise ratio in the final image as compared to an unbinned image or to an image which is binned to the same degree after readout. The spatial resolution of a binned image is necessarily reduced.

Third, the CCD can be operated in frame transfer mode. In this mode, the $\mathrm{CCD}$ operates simultaneously as both a photoelectron storage and collection device. Half of the field of view is physically masked by placing a partial field stop between the specimen and the CCD in a focal plane conjugate to the image plane. An image of the visible half of the field is collected by illumination at one excitation wavelength. After closing the shutter, the collected image is electronically shifted from the unmasked half of the CCD chip to the masked half in under $1 \mathrm{~ms}$. A second image of the same half of the field is then collected by illumination at a second excitation wavelength. The resultant full CCD image shows the same field twice, once for each excitation wavelength (see Fig. 2).

\section{Image collection software}

Image collection and processing was accomplished through menu-driven software modified from a base system, Vista-IPS (Paragon Imaging, Lowell, MA, USA). Time-lapse imaging is accomplished via a set of programs that can direct the collection of up to 1000 images of three separate types (i.e. frame transfer, binned, brightfield, etc) at a user-specified frequency. During image collection, images may be displayed on a monitor (Sanyo Electric, Inc., 


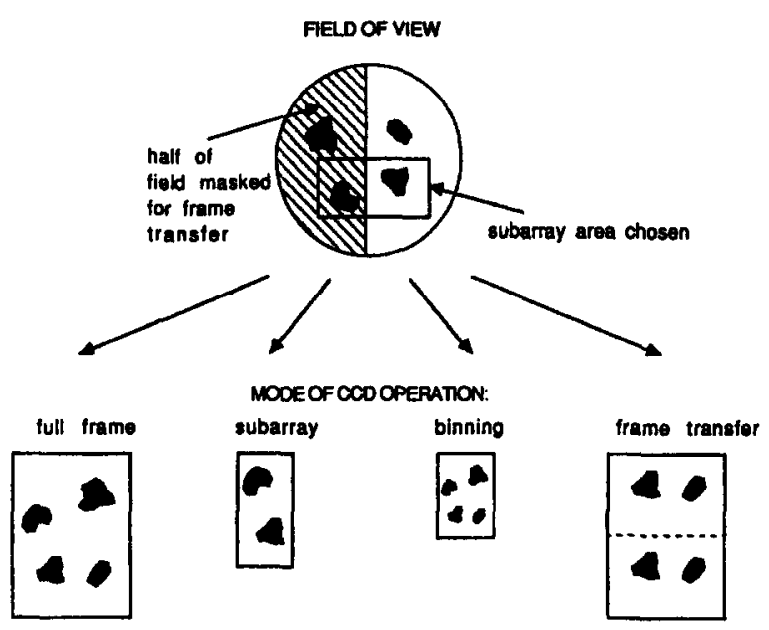

RESULTANT MAGES

Fig. 2 Modes of operation of the CCD. The CCD may be used to take a full frame $390 \times 584$ pixel image or a smaller subarray. Binned images may be collected by combining the charge on neighbouring pixels at the time of readout. Frame transfer imaging allows the collection of two separate images of the same field of view on the partially masked CCD chip before the chip is read

Compton, CA, USA) connected to the CCD camera on the graphics terminal. The latter display is available for concurrent display and image analysis.

\section{Image collection and processing}

Fluorescence images of cells at the two excitation wavelengths were collected using the $\mathrm{CCD}$ frame transfer mode of operation, as described above. Because the SMC spread very thinly on the coverslip surface, typical operation of the CCD with no binning requires a $2000 \mathrm{~ms}$ exposure at $334 \mathrm{~nm}$ and a $200 \mathrm{~ms}$ exposure at $365 \mathrm{~nm} ; 2 \times 2$ binning allowed these exposure times to be reduced by a factor of four. Blank field background images at both wavelengths were taken for each coverslip and subtracted from each of the cell images. The resultant background subtracted images were then split into halves, each half corresponding to one of the original excitation wavelengths, and ratio images (R) were generated, where $R=F_{334} / F_{365}$, the fluorescence intensity at $334 \mathrm{~nm}$ divided by the fluorescence intensity at $365 \mathrm{~nm}$. Autofluorescence contributed only $3-5 \%$ of the total fluorescence at each of the illumination wavelengths. Computations of ratio images and subsequent processing were carried out with floating point precision.

Calibration measurements are taken by imaging three solutions in the flow chamber positioned on the microscope stage: $10 \mu \mathrm{M}$ Fura-2 free acid (Molecular Probes) in phosphate-buffered saline (PBS) supplemented with $2 \mathrm{mM} \mathrm{CaCl}, 10 \mu \mathrm{M}$ Fura-2 free acid in PBS supplemented with $2 \mathrm{mM}$ EDTA and PBS alone (for background subtraction). $R_{\max }=\left(\mathrm{F}_{334} / \mathrm{F}_{365}\right)$ at saturating $\mathrm{Ca}^{2+}, \mathrm{R}_{\min }=$ $\left(\mathrm{F}_{334} / \mathrm{F}_{365}\right)$ at no $\mathrm{Ca}^{2+}$ and $\beta=F_{365}$ (no calcium)/F365(saturating $\mathrm{Ca}^{2+}$ ) were calculated from these images. Use of these calibration measurements led to calculated resting $\left[\mathrm{Ca}^{2+}\right] \mathrm{i}$ in the order of $30 \mathrm{nM}$. As this level seemed rather low in comparison with the resting $\left[\mathrm{Ca}^{2+}\right]$ in other cells reported in the literature $[2,6,10,12,13]$ and in the light of the known systematic bias toward low calculated $\left[\mathrm{Ca}^{2+}\right] \mathrm{i}$ when Fura -2 is in high viscosity or protein-containing media [25], we adopted a simple correction procedure to approximate the differing conditions in the cytosol as compared to PBS. All systematic bias may not be completely removed by this procedure. Corrections for intracellular viscosity were determined by imaging solutions as above but supplemented with $60 \%$ (w/v) sucrose (RY Tsien, personal communication); $\mathbf{R}_{\max }, \mathbf{R}_{\min }$ and $\beta$ are respectively found to be $60 \%$, $95 \%$, and $80 \%$ lower in the high viscosity solutions as compared to PBS. The viscosity-corrected $\beta$ for our imaging system was approximately 1.4 and the corrected $R_{\min }$ and $R_{\max }$ were approximately 0.2 and 0.05 . All three parameters vary across the field of view. Intracellular free $\mathrm{Ca}^{2+}$ was determined according to the equation $\left[\left[\mathrm{Ca}^{2+}\right]_{i}=\mathrm{K}_{\mathrm{d} \beta}[(\mathrm{R}\right.$ $\left.\left.R_{\min }\right) /\left(R_{\max }-R\right)\right]$, where $K_{d}=224 \mathrm{nM}$ is the equilibrium dissociation constant for $\mathrm{Ca}^{2+}$ and Fura-2 [26].

Series of ratio or calcium images calculated as described were then processed by a masking technique to determine the average value of the fluorescence intensity ratio or calcium concentration at various regions in each cell as a function of time. Masking was performed in one of two ways. If the cell of interest did not move, and if there was no drift of the field of view during the experiment, a one bit overlay mask of a region of the cell, corresponding to pixels in the cell image above a user-set threshold grey level value and delimited 

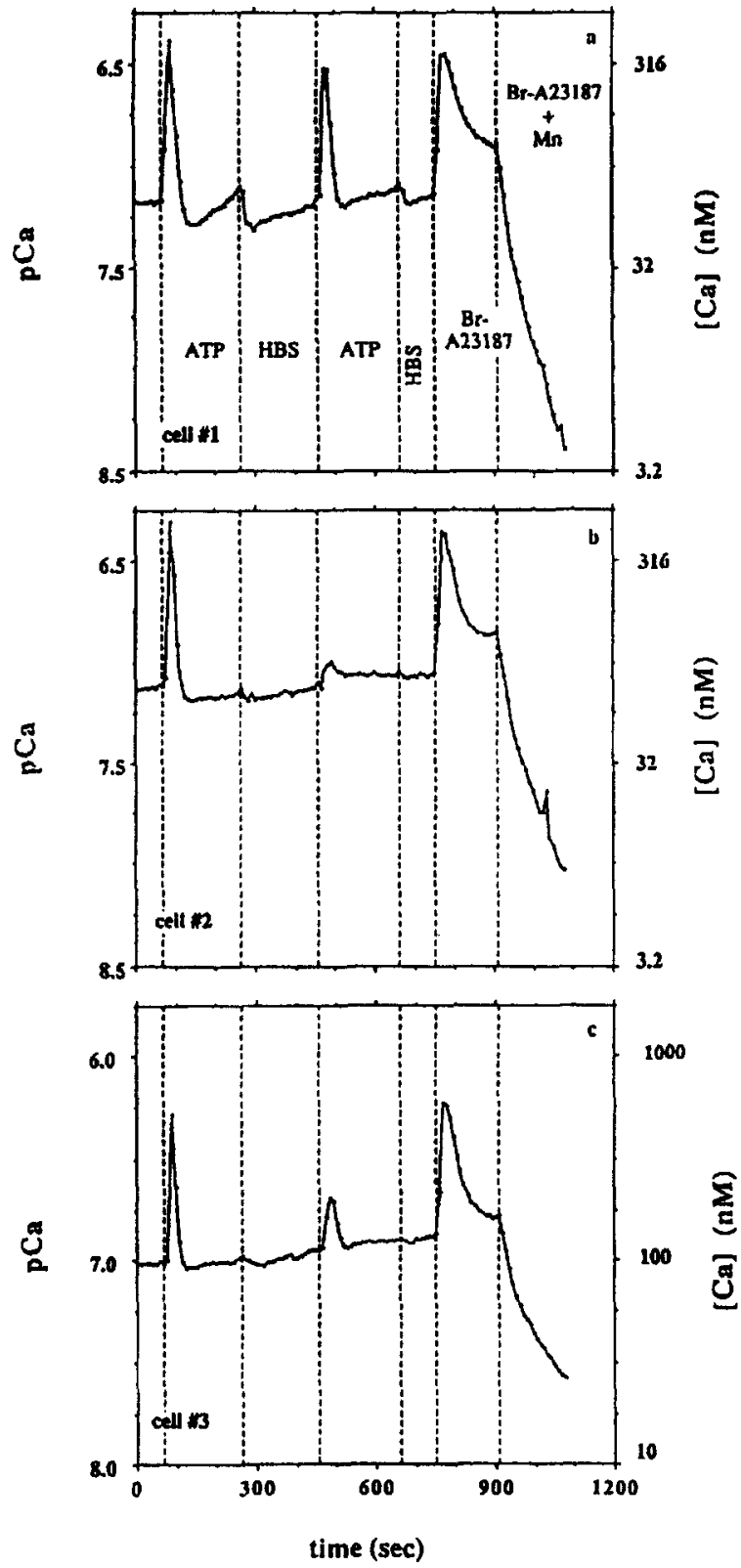

Fig. 3a-c Variations in calcium concentration with time in response to ATP and ionophore for three cells in the same field. Agents were added (ATP, Br-A23187) or removed (HBS) at times indicated by the vertical dashed lines. Agonist concentrations: ATP, $50 \mu \mathrm{M} ; \mathrm{Br}-\mathrm{A} 23187,1 \mu \mathrm{M} ; \mathrm{MnCl}_{2}, 2 \mathrm{mM}$. Images were collected using frame transfer

interactively by the user to regions of interest, was made and applied to each of the images in the time-lapse sequence. The threshold level is determined interactively by the user; typically the level was set such that the image of the cell fluorescence illuminated at $365 \mathrm{~nm}$ was sharply delineated. This usually samples the cell interior but avoids very dim cell extensions. If there was a change in the shape or position of the cell during the experiment, the cells were masked interactively: the user selected the region of interest in each frame of the time-lapse sequence. Pixels in the ratio or calcium image which corresponded to a division by zero in the ratio calculation were excluded during either masking procedure.

Image display in either grey levels or pseudocolour was possible. Ratio or calcium images could be displayed at 10 bit resolution; for this display mode 5 bits of the displayed image derived from the 365 fluorescence image modulate image intensity and 5 bits derived from the ratio or calcium image modulate image colour. This display allows the viewer to simultaneously observe calculated ratio or calcium levels as well as intrinsic fluorescence levels at all points across the cells. Correlation of deviant calculated $\left[\mathrm{Ca}^{2+}\right]$ with above average or below average fluorescence brightness in a pixel or cell region is facilitated. Data collection as described in the previous paragraph was from 32 bit floating point ratio or calcium images and was independent of image display.

\section{Results}

The application of ATP to Fura-2 loaded SMC stimulated a rise in the concentration of intracellular free calcium in the presence of extracellular calcium. In Figure $3 a-c$, plots of intracellular calcium concentration versus time are shown for 3 SMC in a single $390 \times 192$ pixel field. Pairs of images were collected approximately every $9 \mathrm{~s}$ using the frame transfer mode of CCD operation; exposure times of $2000 \mathrm{~ms}$ at $334 \mathrm{~nm}$ and $200 \mathrm{~ms}$ at $365 \mathrm{~nm}$ illumination wavelengths were used. All three cells began with mean intracellular free calcium concentration of $70-100 \mathrm{nM}$ and responded immediately and synchronously to the addition of 50 $\mu \mathrm{M}$ ATP at $75 \mathrm{~s}$, with a rise to a peak of $410-520$ nM calcium. The cells returned to initial or less than initial calcium concentrations about $55 \mathrm{~s}$ after the initial rise. At $270 \mathrm{~s}$, the ATP was removed and cellular calcium levels dropped slightly, remaining roughly constant until a second addition of $50 \mu \mathrm{M}$ 

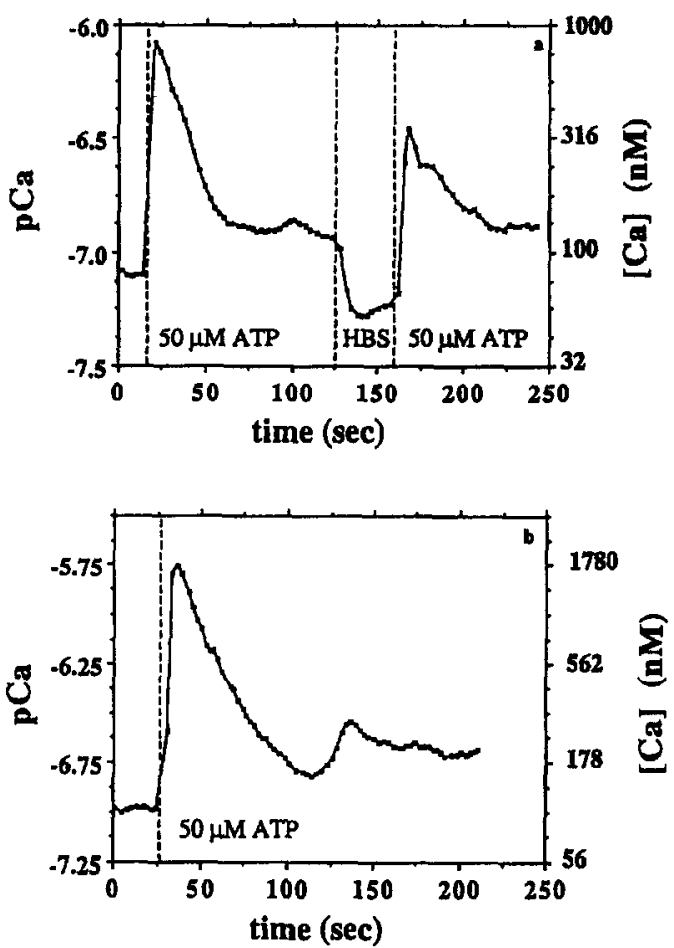

Fig. 4 (a) Variations in calcium concentration with time in response to $50 \mu \mathrm{M}$ ATP for the cell shown in Plate 9. Addition and washout of ATP are indicated by vertical dashed lines. Note that $\left[\mathrm{Ca}^{2+}\right]_{j}$ does not rise until after ATP addition. Images were collected using frame transfer, subarray, and binning capabilities.

(b) Variations in calcium concentration with time in response to $50 \mu \mathrm{M}$ ATP for a single cell. Addition of ATP is indicated by the vertical dashed line. Note that $\left[\mathrm{Ca}^{2+}\right]_{\mathrm{i}}$ does not rise until after ATP addition. Images were collected using frame transfer, subarray and binning capabilities

ATP to the chamber at $465 \mathrm{~s}$. All three cells once again responded, although cells 2 and 3 (Fig. $3 \mathrm{~b}$ and 3c) reached their peaks slightly later than cell 1 (Fig. 3a). The magnitude of the responses in the three cells differed significantly: cells 1,2 and 3 peaked at $300 \mathrm{nM}, 100 \mathrm{nM}$ and $200 \mathrm{nM}$ calcium, corresponding to increases of 230,30 and $90 \mathrm{nM}$ calcium respectively. A second wash removed the ATP, reiurning the calcium levels to near initial values for all three cells. . The addition of $1 \mu \mathrm{M}$ Br-A23187, a non-fluorescent calcium ionophore [27], served to again increase calcium levels. It is interesting to note that the maximum ratio values observed following exposure to the ionophore reached only $60-70 \%$ of their $R_{\max }$ values and in cells 1 and 2 did not reach levels stimulated during the initial ATP addition. Additionally the cells appeared to regulate their calcium levels in the continued presence of the ionophore, as the calcium levels settle at a steady, albeit elevated, value after approximately $100 \mathrm{~s}$. This result suggests that we have not overloaded the capacities of the cells to pump or store free calcium. A final addition of 1 $\mu \mathrm{M} \mathrm{Br}-\mathrm{A} 23187$ and $2 \mathrm{mM} \mathrm{MnCl}_{2}$ was used to quench the Fura-2 fluorescence by allowing the entry of substantial amounts of $\mathrm{Mn}^{2+}$ into the cells. Approximately $80 \%$ of the fluorescence was quenched by this treatment. As $\mathrm{Mn}^{2+}$ quenches only the Fura-2 anion and not Fura-2/AM, the remaining cell-associated fluorescence is due to non-hydrolyzed or partially hydrolyzed Fura-2/AM or to Fura-2 free acid that is isolated from the $\mathrm{Mn}^{2+}$. The former is more likely since the fluorescence ratio $R$ drops to a low value, characteristic of the spectral response of Fura-2/AM [28].

To examine the kinetics of the calcium transients in single cells in more detail, the response of a single cell to ATP was examined by simultaneously using the frame transfer, subarray and binning capabilities of the imaging system. The cell shown in Plate 9 was imaged in a $200 \times 292$ pixel subarray with $2 \times 2$ binning, giving a final image size of 100 $x 146$ pixels. The cell was exposed for $500 \mathrm{~ms}$ at $334 \mathrm{~nm}$ and $50 \mathrm{~ms}$ at $365 \mathrm{~nm}$, and pairs of images were collected approximately every $3 \mathrm{~s}$. Although the image has been binned, note that cellular detail, including thin processes, are clearly visible. In Figure $4 \mathrm{a}$, the corresponding plot of calcium concentration versus time is given. The calcium concentration increased rapidly from a starting level of approximately $80 \mathrm{nM}$ to a peak of $840 \mathrm{nM}$ upon addition of $50 \mu \mathrm{M}$ ATP and then returns to a slightly elevated calcium level of $130 \mathrm{nM}$ over the next minute. The speed of data collection allows us to examine the calcium transients in more detail than for the data of Figure 3. We note that the decrease in calcium concentration is not well characterised by simple exponential decay; this has been observed in many other cells as well (data not shown). A slight secondary rise in calcium at $100 \mathrm{~s}$ is also resolved. The removal of ATP from the extracellular medium causes the intracellular free calcium concentration to fall to slightly lower than its initial value. A second addition of $50 \mu \mathrm{M}$ ATP 
Table 1 Calcium levels in various regions of an individual smooth muscle cell

\begin{tabular}{lccc}
\hline \multirow{2}{*}{ Region examined (Number of pixels in region) } & \multicolumn{3}{c}{ Calcium level (nM) } \\
\cline { 2 - 4 } & Resting* & First peak & Second peak \\
\hline Whole cell (1856) & $81.2 \pm 0.4$ & 835 & 339 \\
& & & \\
All peripheral extensions (363) & $69.4 \pm 1.8$ & 709 & 338 \\
Bottom lamellepodium (231) & $55.7 \pm 2.8$ & 589 & 294 \\
Long extension, top left (80) & $76.1 \pm 3.8$ & 388 & 209 \\
& & & \\
Cell interior, non-lamellepodial (1361) & $86.2 \pm 0.3$ & 904 & 354 \\
Upper half of cell interior (863) & $89.7 \pm 0.2$ & 1062 & 399 \\
Lower half of cell interior (613) & $78.3 \pm 0.6$ & 702 & 295 \\
\hline
\end{tabular}

* Four data points before the first ATP addition were averaged to obtain the resting calcium level. The result is expressed as mean \pm standard error

at $160 \mathrm{~s}$ stimulates a second dramatic rise in calcium concentration. A desensitisation of the ATP response is again suggested, as the second peak has a maximum of only $350 \mathrm{nM}$. The fall from the elevated calcium level to a steady and lower level again occurs in roughly one minute and is clearly not characterised by a single exponential.

To address the spatial dependence of the calcium response to ATP, the cell of Plate 9 and Figure 4a was examined in greater detail. Seven separate regions of the cell were selected and analysed. The temporal dependence of the calcium response was identical from region to region within the cell in that the initiation of both increases in $\left[\mathrm{Ca}^{2+}\right]_{i}$ and the times at which a peak was reached were the same (not shown). However, as may be seen in Plate 9, the resting and peak $\left[\mathrm{Ca}^{2+}\right]_{i}$ levels varied from point to point (see Table 1).

The results of a similar experiment are shown in Figure 4b. Pairs of images were collected approximately every $2.5 \mathrm{~s}$ for a subarray with a $2 \times 2$ binned size of $44 \times 146$ pixels. The addition of 50 $\mu \mathrm{M}$ ATP stimulated a rise in calcium concentration from 100 to $1800 \mathrm{nM}$, followed by a return to a slightly elevated level. As in Figure $4 a$ there is a second minor calcium transient occurring after the first.

The data shown in Figure 5 are the result of an experiment on a field containing 2 cells. Frame transfer $2 \times 2$ binned images were collected approximately every $3.5 \mathrm{~s}$. Cell 2 responds in a fashion similar to the cells of Figure $4:\left[\mathrm{Ca}^{2+}\right]_{\mathrm{i}}$ rises rapidly from approximately $100 \mathrm{nM}$ to $530 \mathrm{nM}$ calcium upon addition of $50 \mu \mathrm{M}$ ATP, followed by a decrease, a strong secondary peak and a second decrease to nearly the initial concentration. As in Figures 3 and 4a, a second addition of $50 \mu \mathrm{M}$ ATP stimulates a less dramatic rise in calcium; in this cell, however, the secondary peak following this second response is nearly equal in beight to the response itself. The addition of $1 \mu \mathrm{M}$ Br-A23187 stimulated a rise in calcium and then a decrease to a steady elevated level; the simultaneous addition of 1 $\mu \mathrm{M}$ Br-A23187 and $2 \mathrm{mM} \quad \mathrm{MnCl}_{2}$ quenched fluorescence and depressed ratio values as in Figure 3. After both the first and second ATP stimulations, a second peak of $\left[\mathrm{Ca}^{2+}\right]_{i}$ delayed about $100 \mathrm{~s}$ after the initial response was seen in this cell.

The calcium levels of cell 1 in Figure 5 have quite a different character than those of cell 2 . The calcium concentration in this cell before stimulation is elevated to approximately $300 \mathrm{nM}$. Stimulated increases in the calcium concentration are observed for cell 1 in response to both ATP and Br-A23187; the magnitude of the increases in cell 1 are less than in cell 2 for the first addition of ATP, greater than in cell 2 for the second addition of ATP, and approximately the same in the two cells for the addition of Br-A23187. The data for cell 1 appear to be much noisier than for cell 2 or for the cells shown in Figures 3-5 and Plate 9. An examination of the original data (not shown) indicates that the noisy cell is at least as bright as cell 2 for both wavelengths of illumination; thus the noise is not due to a low signal to noise ratio for cell 1 as compared with cell 2 (see Discussion).

In Figures $3-5\left[\mathrm{Ca}^{2+}\right]_{i}$ transients subsequent to the initial response spike can be discerned in several 


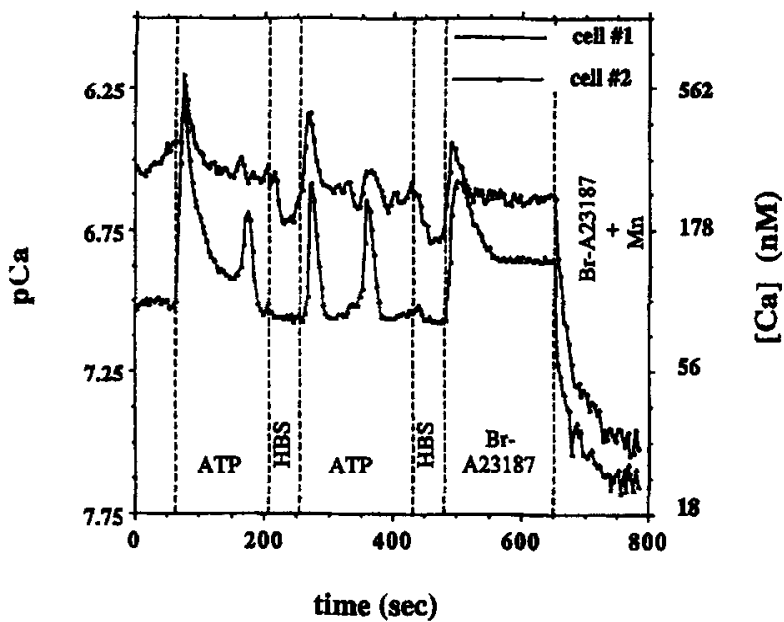

Fig. 5 Variations in calcium concentration with time in response to ATP and ionophore for two cells in the same field. Agents were added or removed at times indicated by the vertical dashed lines. Agonist concentrations: ATP, $50 \mu \mathrm{M}$; Br-A23187, $1 \mu \mathrm{M}$; $\mathrm{MnCl}, 2 \mathrm{mM}$. Images were collected using frame transfer, subarray and binning capabilities

individual cells. That these subsequent transients persist repetitively is shown in Figure 6 which demonstrates that SMCs respond to ATP stimulation both by a rapid $\left[\mathrm{Ca}^{2+}\right]_{i}$ transient and a sustained train of rises in $\left[\mathrm{Ca}^{2+}\right]_{i}$ which have been termed oscillations in studies of other cell types [12, 13, 29]. The data in Figure 6 are from a $194 \times 146$ pixel field; exposure times of $700 \mathrm{~ms}$ at $334 \mathrm{~nm}$ and $90 \mathrm{~ms}$ at $365 \mathrm{~nm}$ were used. Frame transfer, $2 \times 2$ binned images were collected approximately every $2.3 \mathrm{~s}$. The fluorescence ratio $R$, normalised such that $R_{\text {prestimulus }}=1$, is plotted versus time. As noted elsewhere [2] and as stated later in the Discussion section, the 334/365 image pair produces ratio values which are nearly linear with $\mathrm{pCa}$ over the range of $100 \mathrm{nM}$ to $1 \mu \mathrm{M}$. Thus the $\mathrm{R}$ values reported here are representative of changes in $\mathrm{pCa}$ in the cells. The lack of response of the cells to platelet derived growth factor (PDGF-BB, recombinant from $E$. coli, Bachem Inc., Torrance, CA, USA), is likely due to the slowness of recovery of PDGF receptors on these cells after trypsinisation; the flatness of the traces indicates the stability of $\left[\mathrm{Ca}^{2+}\right]_{i}$ in the cells prior to the ATP response. An injection of $50 \mu \mathrm{M}$ ATP at $476 \mathrm{~s}$ stimulated $\left[\mathrm{Ca}^{2+}\right]_{\mathrm{i}}$ increases in all 5 cells. The $\left[\mathrm{Ca}^{2+}\right]_{i}$ levels in 4 of the 5 cells then began to oscillate: the oscillation

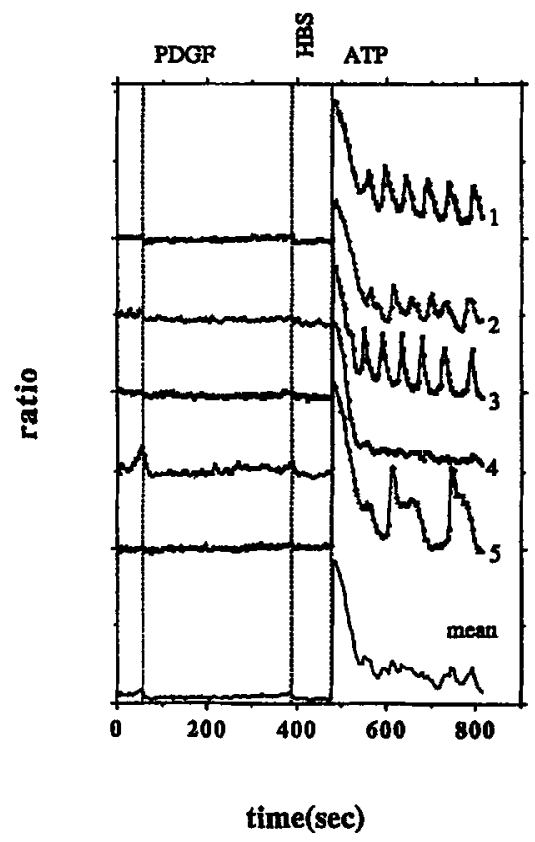

Fig. 6 Responses of five SMCs exposed to $75 \mathrm{ng} / \mathrm{ml} \mathrm{PDGF}$ followed by $50 \mu \mathrm{M}$ ATP. The PDGF was washed from the cell chamber at $\mathrm{t}-385$ s. Cell responses are plotted as fluorescence ratio $\left(R\right.$ - $F_{33} / F_{365}$ ) which is proportional to $\mathrm{pCa}$ (see Discussion), and are shifted vertically for clarity. Variation of $R$ over the microscope field has been corrected. The average response of the five cells is shown by the bottom trace labeled 'mean'

frequencies in cells $1,2,3$ and 5 are, respectively, $1.3 \mathrm{~min}^{-1}, 1.4 \mathrm{~min}^{-1}, 1.2 \mathrm{~min}^{-1}$ and $0.45 \mathrm{~min}^{-1}$. Although the initial or primary calcium peaks of all 5 cells are synchronous to within the time resolution of the experiment, the ensuing oscillations are asynchronous from cell to cell as shown by the bottom trace in Figure 6 which is the average of the 5 cell responses. Finally, the oscillations do not show all the same characteristics. Cells 1 and 3 show highly regular and simple oscillations, cell 2 demonstrates less regular oscillations and cell 5 shows oscillations with an irregular shape. One of the cells, (cell 4), fails entirely to oscillate.

\section{Discussion}

\section{Imaging system}

One cell in Figure 5 has a much higher resting $\left[\mathrm{Ca}^{2+}\right]_{\mathrm{i}}$ than other cells shown in this report. We 
find that approximately $20 \%$ of the cells we have observed (of a total $>150$ ) have significantly elevated resting $\left[\mathrm{Ca}^{2+}\right]_{i}$ similar to that of cell 1 of Figure 5. In every case, the fluctuations of measured $\left[\mathrm{Ca}^{2+}\right]_{i}$ about its mean value are a few times more than those in cells with lower 'normal' resting $\left[\mathrm{Ca}^{2+}\right] \mathrm{i}$. In order to determine whether these fluctuations are due to the cells themselves, or to the measurement technique, we have analysed the dependence of fluorescence ratio, sensitivity and relative noise versus $\mathrm{pCa}$ for Fura-2 determination of $\left[\mathrm{Ca}^{2+}\right] \mathrm{i}$. Since the wavelength pair $(334 / 365 \mathrm{~nm})$ we employ for Fura-2 ratio imaging differs from the more commonly used wavelength pair (340/380 $\mathrm{nm}$ ), we additionally compare these properties for the two wavelength pairs. As can be readily discerned by examining the excitation spectra for Fura-2 at various $\mathrm{Ca}^{2+}$ concentrations [26], the absolute value of ratio $R$ for the $334 / 365 \mathrm{~nm}$ wavelength pair is always less than that for $340 / 380$ $\mathrm{nm}$ at any value of $\mathrm{pCa}$. Figure $7 \mathrm{a}$ is a plot of $\mathrm{R}$ versus $\mathrm{pCa}$ for both wavelength pairs, normalised such that $R=1$ at $\left[\mathrm{Ca}^{2+}\right]=\mathrm{K}_{\mathrm{d}}$ for both curves. This normalisation is equivalent to adjusting fluorescence exposure time or excitation intensity to produce equivalent brightness images at $\left[\mathrm{Ca}^{2+}\right]=$ $224 \mathrm{nM}$ and thus allows us to compare the two wavelength pairs on the same scale. Over the range of pCa typically encountered in cells, $100 \mathrm{nM}$ to 1 $\mu \mathrm{M}$, the $334 / 365$ ratio is nearly linear with $\mathrm{pCa}$ while $340 / 380$ is less so (inset, Fig. 7a). Thus the grey levels of $334 / 365$ ratio images are reasonably representative of $\mathrm{pCa}$, allowing one to estimate the calcium response of a cell with only three image computation steps (two subtractions and one division). The sensitivity of the response of $R$ to a change in $\mathrm{pCa}(\delta \mathrm{R} / \delta \mathrm{pCa})$ for the two wavelength pairs is not shown in Figure $7 \mathrm{~b}$. The sensitivity of the $340 / 380$ pair is greater than that for $334 / 365$ over most of the physiological range of pCa. Note that the peak sensitivity of the 334/365 pair is in the middle of the physiological range $(430 \mathrm{nM})$ while that for the $340 / 380$ range is at the high end ( 2400 nM).

For a single measurement, the relative uncertainty of the ratio in any given pixel is the sum of relative uncertainties in the numerator and denominator image pixels, it is straightforward to derive the expression for the uncertainty in $\mathbf{R}$ :

$$
\begin{aligned}
& \frac{\Delta R}{R}=\left(\frac{\Delta F}{f ., \text { min }_{\text {min }}}\right)\left(K_{d}+\left[C a^{2+}\right]\right) . \\
& \quad \beta\left\{\left(\beta K_{d} R_{\min }+\left[C a^{2+}\right] R_{\max }\right)^{-1}+\left(\beta K_{d}+\left[C a^{2+}\right]\right)^{-1}\right\}
\end{aligned}
$$

where $\Delta R$ is the absolute uncertainty (or noise) in $R$, $\Delta F$ is the typical noise level in a pixel, $f_{d, \min }$ is the intensity of fluorescence excited at the denominator wavelength in the absence of calcium, and $R_{\max }$, $R_{\min }, \beta$, and $K_{d}$ are as defined earlier. For $a$ determination of the mean $\left[\mathrm{Ca}^{2+}\right]_{i}$ based on multiple data samples the standard deviation of $R$ follows a more complicated expression. Our expression is the upper bound to the standard deviation. Fluctuations in the number of calcium ions in the region represented by a pixel as well as diffusive or $\mathrm{Ca}^{2+}$-binding fluctuations in Fura-2 fluorescence are assumed to occur on a timescale much shorter than our shortest exposure time, $50 \mathrm{~ms}$. For our images, the dominant contribution to pixel grey level uncertainty is camera noise. $\Delta \mathrm{F} / \mathrm{F}$ is of the order of 0.05 for the brightest regions in the cell. Figure $7 \mathrm{c}$ shows the relative uncertainty in $\mathrm{R}$ as a function of $\mathrm{pCa}$ for the two wavelength pairs, normalised so that $\mathrm{f}_{365, \mathrm{~min}}=\mathrm{f}_{380, \min }$ at $\left[\mathrm{Ca}^{2+}\right]_{\mathrm{i}}=\mathrm{K}_{\mathrm{d}}$, again to allow us to compare the two wavelength pairs at the same scale. The relative noise for the $334 / 365$ image pair decreases from low to high $\left[\mathrm{Ca}^{2+}\right]$, which, in combination with the dependence of $R$ on $\mathrm{pCa}$ for this wavelength pair, indicates that the absolute uncertainty in $\mathbf{R}$ is relatively constant over the whole range of $\mathrm{pCa}$. The most important measurement uncertainty is shown in Figure $7 d$ in which relative fluctuations were measured $\mathrm{pCa}$ $(\triangle \mathrm{pCa} / \mathrm{pCa})$ are plotted versus actual $\mathrm{pCa}$. We have included in this plot contributions due to fluctuations in all the measured parameters $R, \beta$, $R_{\min }$ and $R_{\max }$. As the cell images which are used to calculate $R$ are ten times dimmer than those used to calculate $\beta, R_{\min }$ and $R_{\max }$ for our experiments, the relative fluctuations in the calibration images are ten fold lower than those in the cell images. Again the relative uncertainty for the 340/380 wavelength pair has been normalised to that for $334 / 365$. $\triangle \mathrm{pCa} / \mathrm{pCa}$ is lower for the $340 / 380$ wavelength pair except over the pCa range from 6.6-6.9 (126-250 $\mathrm{nM})$. Note that the relative uncertainty for the 

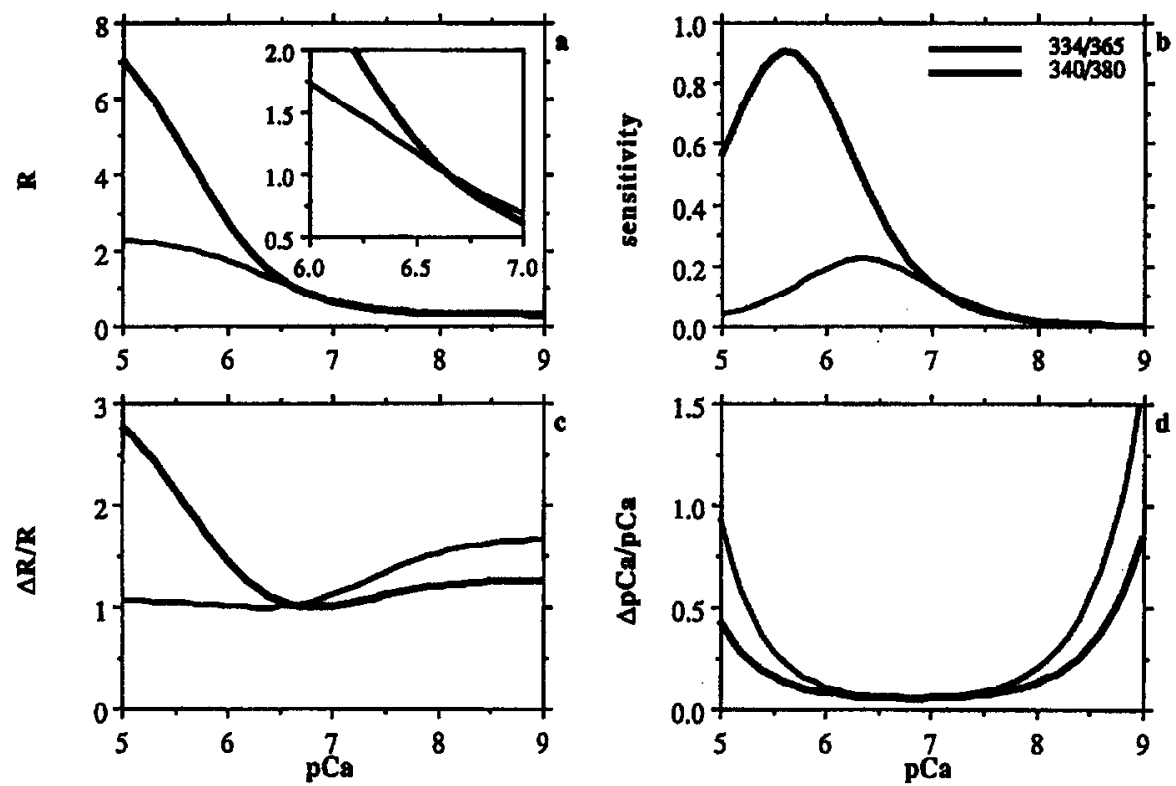

Fig. 7 Ratio (a), $\delta \mathrm{R} / \delta \mathrm{pCa}(\mathrm{b}), \Delta \mathrm{R} / \mathrm{R}$ (c) and $\Delta \mathrm{pCa} / \mathrm{pCa}$ vs $\mathrm{pCa}$ for the $334 / 365 \mathrm{~nm}$ and $340 / 380 \mathrm{~nm}$ wavelength pairs. Spectral data were taken from [25] to obtain $R_{\min }, R_{\max }$ and $\beta$. No correction for viscosity was made. The plot of $\Delta R / R(c)$ assumes $\Delta F / f_{D}, \min =1$, i.e. corrected values of $\Delta \mathrm{R} / \mathrm{R}$ for any given pixel must be multiplied by the measured $\Delta \mathrm{F} / \mathrm{f}, \min$. In the plot of $\Delta \mathrm{pCa} / \mathrm{pCa}$ (d), the $340 / 380 \mathrm{~nm}$ wavelength curve has been normalised to the $334 / 365 \mathrm{~nm}$ curve at the point at which $\mathrm{pCa}-\mathrm{pK} d . \Delta \mathrm{F} / \mathrm{fD}_{\mathrm{D}, \min }-0.005$ for the images generating $R$ while $\Delta F / f_{D, \min }=0.005$ for the images generating $R_{\min } R_{\max }$ and $\beta$. See text for details

$334 / 365$ wavelength pair is only $8 \%$ greater at $\mathrm{pCa}$ $=6.5$ than at $\mathrm{pCa}=7.0$. Using this fact to interpret the data of Figure 5, it appears that the fluctuations in the upper trace (cell 1) are not due to instrumental noise. As stated earlier, the absolute signal detected for cell 1 was no less than that detected for cell 2, ruling out a difference in the signal/noise ratio between the two cells as an explanation. Thus it appears that the fluctuations associated with cell 1 arise from intrinsic fluctuations in $\left[\mathrm{Ca}^{2+}\right]$ i; the cellular basis of this calcium noise is not apparent.

The operation of the $\mathrm{CCD}$ in one or more specialised modes offers a variety of options to the user. Collection of a single image at full resolution on the CCD requires approximately $1.5 \mathrm{~s}$ for readout and image storage. Because fluorescence ratio imaging requires two separate images of the same field, each corresponding to a different excitation wavelength, operation of the $\mathrm{CCD}$ in this mode would require at least $3.0 \mathrm{~s}$ for the collection of data to compute one ratio image, exclusive of actual exposure times. For this reason, it is often desirable to collect data on only one portion of the entire field, a subarray. The clear advantages, particularly for the collection of data to form ratio images, are faster interframe, readout and storage times. Binning the charge as it is collected from the $\mathrm{CCD}$ also offers the advantage of faster image transfer times; this advantage couples with that of shorter exposure times for a fixed image brightness. The use of this technique is particularly helpful for images of $\mathrm{Ca}^{2+}$ transients in SMC, for full frame unbinned images require a total exposure time in the order of $2 \mathrm{~s}$. Although the spatial resolution of the binned image is reduced in comparison with an unbinned image, individual cells and some intracellular structure are still distinguishable even with $3 \times 3$ binning.

Operation of the CCD in frame transfer mode, employing it simultaneously as a photoelectron storage and collection device, is particularly suited to Fura- 2 ratio imaging because both images needed for the ratio are collected with minimal time between images. Errors due to temporal misregistry between numerator and denominator images are greatest when $\mathrm{Ca}^{2+}$ is rapidly changing or when cells move rapidly. For frame transfer imaging with our system, the predominant cause of temporal misregistry is the exposure time of the $334 \mathrm{~nm}$ image. 
$\mathrm{Ca}^{2+}$ transients in $\mathrm{SMC}$

In an earlier study, Tawada and co-workers [20] demonstrated ATP-induced calcium transients in suspensions of cultured smooth muscle cells from rat aorta. We extend those observations to individual cultured swine aortic smooth muscle cells attached to a substrate, and examine detailed kinetics of the calcium transient Rapid imaging of cells, taking pairs of images every $2-3 \mathrm{~s}$, allows us to resolve features in the $\left[\mathrm{Ca}^{2+}\right]_{i}$ response curves that are not readily apparent with slower imaging. For example, the data on the decline of the ATP-induced calcium transient shown in Figure 3 give no indication of the subtle features we note with the data of Figures 4 and 5 . The slight secondary calcium transients observed in Figures 4 and 5 would be missed entirely if pairs of images were collected more slowly. The asynchronous sustained oscillations of $\left[\mathrm{Ca}^{2+}\right]_{i}$ shown in Figure 6 would appear as noise with lower time resolution data collection. The pattern of these oscillations varies widely from cell to cell as has been reported for other cells $[29,30]$; the data reported in Figure 6 are typical of our observations of more than 150 SMCs. We find that most $(\sim 70-80 \%)$ of the cells with resting levels of $\left[\mathrm{Ca}^{2+}\right]_{i}$ near $100 \mathrm{nM}$ display calcium oscillations after the ATP-stimulated transient when observation times extend for 2 minutes or longer, and that the oscillations require the continued presence of the stimulant. A more detailed study of these oscillations is in progress.

The data shown here support the postulate that desensitisation of the ATP-induced calcium response occurs with continued exposure to ATP and extracellular calcium. After an initial exposure of the cells to ATP for approximately $100-200 \mathrm{~s}$ and a brief (50-150 s) wash, an identical dose of ATP produces a significantly decreased calcium response. Benham and Tsien [21] have shown that ATP. activated $\mathrm{Ca}^{2+}$ channels in aortic smooth muscle inactivate within $\sim 2 \mathrm{~s}$ after application of $1 \mu \mathrm{M}$ ATP. As the decline of the whole-cell $\mathrm{Ca}^{2+}$ response to ATP we find has a considerably longer time course than $2 \mathrm{~s}$, either a second mode of desensitization or altered ATP-activated $\mathrm{Ca}^{2+}$ channel activity in our cells is indicated. The former is supported by the fact that stimulation of SMC with
ATP in $\mathrm{Ca}^{2+}$-free, EGTA-containing HBS produces the initial $\left[\mathrm{Ca}^{2+}\right] \mathrm{i}$ transient (not shown), implicating release of calcium from intracellular stores as the primary source of the initial rise in $\left[\mathrm{Ca}^{2+}\right]$.

Elevated intracellular calcium levels are also observed after the addition of Br-A23187. The fluorescence ratio in these cells does not, however, reach $R_{\max }$ levels and, in the cells examined, this response is less in magnitude than the initial response to ATP. The subsequent decline of calcium levels to a steady though elevated level suggests that SMCs regulate their calcium levels to some degree in the continued presence of the ionophore. The addition of Br-A23187 together with $\mathrm{Mn}^{2+}$ leads to a quenching of Fura-2 fluorescence, suggesting that $\mathrm{Mn}^{2+}$ is entering ion channels opened by the ionophore [3]. The fact that not all of the cell-associated fluorescence is quenched by this treatment and that the ratio values of the cells drop dramatically when $\mathrm{Mn}^{2+}$ is added (Figs 3,6) indicates that not all of the Fura-2/AM is completely hydrolysed by SMCs. This result complicates our measurement of $\left[\mathrm{Ca}^{2+}\right]_{i}$ since the contribution of Fura-2/AM fluorescence tends to artifactually depress measured $\left[\mathrm{Ca}^{2+}\right] \mathrm{i}$. Since the Fura-2/AM may redistribute within a cell during our measurement interval, we have chosen not to attempt a further correction for this artifact.

Careful examination of Plate 9 shows that the apparent distribution of $\left[\mathrm{Ca}^{2+}\right]_{i}$ is heterogeneous, even in unstimulated cells. It is quite likely that some of the Fura-2 anion is entrapped within organelles such as sarcoplasmic reticulum and mitochondria and that these regions report higher $\left[\mathrm{Ca}^{2+}\right]_{i}$ than does the cytosol. A recent report [25] indicates that interaction of Fura-2 with intracellular macromolecules can greatly affect both $K_{d}$ and the spectral properties of Fura-2. This fact, coupled with an uncertainty in the true intracellular viscosity of an individual cell cast doubt on the accuracy of the absolute calibration of calcium that we report. However, the details of kinetics described here are not significantly affected by such uncertainties.

In conclusion, the charge-coupled device imaging system we describe is well suited to the rapid and accurate ratiometric imaging of $\left[\mathrm{Ca}^{2+}\right] \mathrm{i}$ in individual cells and of multiple cells in the same field of view. The data reported here describe subtle features in 
the calcium transients in SMC exposed to ATP and Br-A23187.

\section{Acknowledgements}

The authors wish to acknowledge the assistance of Catherine Randall in data acquisition and analysis. Cell culture was done by Shangzbe $\mathrm{Xu}$. This work was supported by the NIH under grant HL-38130 and the NSF under grant DMB-8803826.

\section{References}

1. Pandol SJ. Schoeffield MS. Fimmel CJ. Muallem S. (1987) The agonist-sensitive calcium pool in the pancreatic acinar cell: Activation of plasma membrane $\mathrm{Ca}^{2+}$ influx mechanism. J. Biol. Chem., 262, 16963-16968.

2. Gonzalez FA. Gross DJ. Heppel LA. Webb WW. (1988) Studies on the increase in cytosolic free calcium induced by epidermal growth factor, serum and nucleotides in individual A431 cells. J. Cell Physiol., 135, 269-276.

3. Hallam TJ. Jacob R. Merritt JE. (1988) Evidence that agonists stimulate bivalent-cation influx into human endothelial cells. Biochem. J., 255, 179-184.

4. Merritt JE. Hallam TJ. (1988) Platelets and parotid acinar cells have different mechanisms for agonist-stimulated divalent cation entry. J. Biol. Chem., 263, 6161-6164.

5. Sage SO. Rink TJ. (1987) The kinetics of changes in intracellular calcium concentration in Fura-2-loaded human platelets. J. Biol. Chem., 262, 16364-16369.

6. Gonzalez FA. Heppel LA. Gross DJ. Webb WW. Parries G. (1988) The rapid desensitization of receptors for platelet derived growth factor, bradykinin, and ATP: Studies on individual cells using quantitative digital video fluorescence microscopy. Biochem. Biophys. Res. Commun., 151, 1205-1212.

7. Sommerville LE. Hartshome DJ. (1986) Intracellular calcium and smooth muscle contraction. Cell Calcium, 7, 353-364.

8. Bond M. Kitazawa T. Somlyo AP. Somlyo AV. (1984) Release and recycling of calcium by the sarcoplasmic reticulum in guinea-pig portal vein smooth muscle. $J$. Physiol., 355, 677-695.

9. Somlyo AV. Bond M. Somlyo AP. Scarpa A (1985) Inositol trisphosphate-induced calcium release and contraction in vascular smooth muscle. Proc. Natl Acad. Sci. USA, 82, 5231-5235.

10. Tsien RY. Rink TJ. Poenie M. (1985) Measurement of cytosolic free $\mathrm{Ca}^{2+}$ in individual small cells using fluorescence microscopy with dual excitation wavelengths. Cell Calcium, 6, 145-157.

11. Williams DA. Fogarty KE. Tsien RY. Fay FS. (1985) Calcium gradients in single smooth muscle cells revealed by the digital imaging microscope using Fura-2. Nature, 318, 558-561.

12. Jacob R. Merritt JE. Hallam TJ. Rink RJ. (1988) Repetitive spikes in cytoplasmic calcium evoked by histamine in human endothelial cells. Nanure, 335, 40-45.

13. Ambler SK. Poenie M. Tsien RY. Taylor P. (1988) Agonist-stimulated oscillations and cycling of intracellular free calcium in individual cultured muscle cells. J. Biol.
Chem., 263, 1952-1959.

14. Hiraoka Y. Sedat JW. Agard DA. (1987) The use of a charge-coupled device for quantitative optical microscopy of biological structures. Science, 238,36-41.

15. Comnor JA. (1988) Fluorescence imaging applied to the measurement of $\mathrm{Ca}^{2+}$ in mammalian neurons. In: Grinnel AD. Armstrong D. Jackson MB. eds. Calcium and ion channel modulation. New York, Plenum, pp. 395-406.

16. Gordon JL. (1986) Extracellular ATP: effects, sources, and fate. Biochem. J., 233, 309-319.

17. Burnstock $G$. Kennedy C. (1986) A dual function for adenosine 5'-triphosphate in the regulation of vascular tone. Circ. Res., 58, 319-330.

18. Ugurbil K. Holmsen H. (1981) Nucleotide compartmentalization: Radioisotopic and nuclear magnetic resonance studies. In: Gordon JL. ed. Platelets in biology and pathology. Amsterdam, Elsevier, pp. 146-147.

19. Slakey LL. (1985) Extracellular nucleotide hydrolysis and integration of signalling. In: Lands WEM. ed. Biochemistry of arachidonic acid metabolism. Boston, Martinus Nijhoff, pp. 323-341.

20. Tawada Y. Furudawa K. Shigekawa M. (1987) ATP-induced calcium transients in cultured rat aortic smooth muscle cells. J. Biochem., 102, 1499-1509.

21. Benham CD. Tsien RW. (1987) A novel receptor-operated $\mathrm{Ca}^{2+}$-permeable channel activated by ATP in smooth muscle cells: Nature, 328, 275-278.

22. Goldman SJ. Dickinson ES. Slakey LL. (1983) Effect of adenosine on synthesis and release of cyclic AMP by cultured vascular cells from swine. J. Cyclic Nucleotide Res., 9, 69-78.

23. Libby P. O'Brien KV. (1983) Culture of quiescent arterial smooth muscle cells in a defined serum-free medium. J. Cell Physiol., 115, 217-223.

24. Meltzer RJ. (1969) Spectographs and monochromators. In: Kingslake R. ed. Applied optics and optical engineering. New York, Academic Press, pp. 47-84.

25. Konishi M. Olson A. Hollingworth S. Baylor SM. (1988) Myoplasmic binding of Fura-2 investigated by steady-state fluorescence and absorbance measurements. Biophys. J., 54, 1089-1104.

26. Grynkiewicz G. Poenie M. Tsien RY. (1985) A new generation of $\mathrm{Ca}^{2+}$ indicators with greatly improved fluorescence properties. J. Biol. Chem., 260, 3440-3450.

27. Deber CM. Tom-Kun J. Grinstein S. (1985) Bromo-A23187: A nonfluorescent calcium ionophore for use with fluorescent probes. Anal. Biochem., 146, 349-352.

28. Scanlon M. Wiliams DA. Fay FS. (1987) A Ca ${ }^{2+}$-insensitive form of Fura-2 associated with polymorphonuclear leukocytes: Assessment and accurate $\mathrm{Ca}^{2+}$ measurement. J. Biol. Chem., 262, 6308-6312.

29. Berridge MJ. Galione A. (1988) Cytosolic calcium oscillators. FASEB J, 2, 3074-3082.

30. Prentki M. Glennon MC. Thomas AP. Morris RL. Matschinsky FM. Corkey BE. (1988) Cell specific patterns of oscillating free $\mathrm{Ca}^{2+}$ in carbamylcholine-stimulated insulinoma cells. J. Biol. Chem., 263, 11044-11047.

Please send reprint requests to: Dr D. J. Gross, Department of Biochemistry and Program in Molecular and Cellular Biology, University of Massachusetts, Amherst, MA 01003, USA 